\section{A fortuna e os limites do bumano}

Martha NUSSBAUM. A fragilidade da bondade: fortuna e ética na tragédia e na filosofia grega. São Paulo, Martins Fontes, 2009. 486 páginas.

\section{Bernardo Ferreira}

Quando o livro A fragilidade da bondade: fortuna e ética na tragédia e na filosofia grega [The fragility of goodness: luck and ethics in greek tragedy and philosophy] foi publicado em 1986, sua autora, Martha Nussbaum, era relativamente desconhecida fora do meio universitário especializado. Com formação em letras clássicas e filosofia, ela trazia em seu currículo a tradução e o comentário (o primeiro a ser feito desde o século XIII) de um texto de Aristóteles sobre o movimento dos animais ${ }^{1}$ e uma série de artigos especializados sobre temas clássicos e algumas incursōes episódicas sobre as relaçōes entre filosofia moral e literatura. No intervalo de tempo que separa a publicação do livro e sua tradução brasileira, ${ }^{2}$ Martha Nussbaum tornou-se uma das figuras mais proeminentes da filosofia no mundo anglo-saxão. Seus interesses intelectuais estenderam-se para além do âmbito no qual sua formação inicialmente ocorrera e foram acompanhados de um envolvimento cada vez maior no debate público norte-americano e uma ênfase crescente nos temas da filosofia política. Uma inspeção superficial no conjunto de suas publicaçóes nos permite ter uma ideia de alguns dos temas com que, desde então, ela veio a se ocupar: o desenvolvimento humano e o ponto de vista das capacidades, o papel das emoções na condução da vida moral e política, as relaçôes entre literatura e filosofia, o problema da justiça e os limites da perspectiva contratualista, o tema dos direitos de mulheres, minorias sexuais e animais, a questão do patriotismo e do cosmopolitismo, a clonagem de seres vivos, a democracia e a violência religiosa na Índia. Nesse mesmo ínterim, as filiações institucionais de Martha Nussbaum mudaram; até meados dos anos de 1990 ela atuou como professora de filosofia e letras clássicas na Brown University, transferindo-se, então, para a universidade de Chicago como professora de ética e direito.

A fragilidade da bondade foi o livro que projetou Martha Nussbaum como um nome de destaque no mundo intelectual e universitário norte-americano. $\mathrm{O}$ livro alcançou uma rápida repercussão e, a despeito de sua extensão e do caráter exigente de muitas de suas discussões, em pouco tempo foi objeto de várias reimpressões. O sucesso editorial e a acolhida favorável conviveram, entretanto, com severas reservas, oriundas principalmente de estudiosos de filosofia antiga. ${ }^{3}$ Tal fato não chega a ser surpreendente, quando consideramos a ambição do projeto e a maneira como o livro explora aquela que pode ser considerada sua questão principal. Trocando em miúdos, pode-se dizer que o volume busca investigar, a partir da discussão da tragédia grega do século $\mathrm{V}$ a.C. e dos textos filosóficos do século IV a.C., as tensóes entre o papel da fortuna na existência humana e a aspiração a uma vida moralmente realizada. Um dos eixos dessa discussão reside na ideia de que pode existir "uma lacuna entre ser uma pessoa boa e conseguir viver uma vida humana florescente" (p. xiii). ${ }^{4} \mathrm{O}$ livro, como observa a própria autora, apresenta dois níveis de análise articulados entre si: um de caráter histórico e outro de fundo filosófico. Por um lado, diz ela, "há um argumento histórico geral a respeito do desenvolvimento do pensamento grego sobre nossas questôes; ele está estreitamente vinculado a um argumento filosófico geral sobre os méritos de várias propostas de vida auto-suficiente" (p. xxxvii). Essas afirmaçôes, inseridas no início do livro, não devem nos enganar, pois os dois níveis do argumento não estão no mesmo plano. A fragilidade da bondade, como assinalou um dos seus críticos, não pede para ser abordado como uma incursão no campo da história das ideias. Nesse particular, pode-se dizer que muitas questôes pertinentes à própria temática do livro permanecem insuficientemente tratadas. A sofística e a historiografia grega, contemporâneas dos autores trágicos e da reflexão filosófica de Sócrates não são discutidas; os usos e o lugar do conceito de tuch (sorte, fortuna) no pensamento grego dos séculos V e IV a.C. são analisados de forma relativamente genérica; as relaçôes entre tragédia, filosofia e polis tampouco são exploradas de maneira mais detida. ${ }^{5} \mathrm{~A}$ força do texto reside, quero crer, no modo como o significativo conhecimento do corpus textual da antiguidade clássica e a competência filológica de sua autora se conjugam à abordagem 
de um problema filosófico. Não estamos diante, portanto, de uma típica pesquisa especializada sobre o pensamento moral antigo. A extensa erudição mobilizada e o pormenor das exegeses dos textos clássicos estão à serviço da tentativa de investigar uma questão no terreno da filosofia moral, e o "argumento histórico geral” do livro está, em última análise, condicionado pelos interesses filosóficos que orientam a discussão. Nesse sentido, pode-se dizer que Martha Nussbaum analisa seu problema a partir dos gregos, e não exclusivamente nos gregos. Ao mesmo tempo, não me parece indiferente que esta investigação de um problema de filosofia moral se faça sob a forma de um retorno ao pensamento ético dos gregos. É evidente que a formação intelectual da autora a conduzia nessa direção. A pergunta, porém, que talvez seja mais interessante de se colocar é por que o problema filosófico específico que ela se dispôs a abordar no livro - as relaçôes entre ética e fortuna - pôde se tornar atraente para uma especialista em estudos clássicos. Vejamos esse ponto com um pouco mais de atenção.

A própria autora indica na abertura do livro que o projeto de escrevê-lo ganhou forma quando entrou em contato com a reflexão moral do filósofo inglês Bernard Williams. Mais especificamente, A fragilidade da bondade dialoga com a ideia de "fortuna moral" (moral luck) introduzida por Williams no âmbito do pensamento filosófico anglo-saxão no artigo "Moral luck" (Williams, 1981). ${ }^{6}$ A noção de "fortuna moral" tem como seu principal alvo as concepçóes éticas derivadas da obra de Kant. Para Williams, um dos equívocos do racionalismo e da pretensão de universalidade dessas concepções está em sua ênfase na impermeabilidade da injunção moral em face das circunstâncias. A liberdade e a dignidade do agente, nessa perspectiva, residem na sua autonomia em relação a todo tipo de condicionamento exterior. O sujeito moral é livre justamente porque seus juízos e suas deliberaçōes não são dependentes de quaisquer condiçóes externas, mas sim de uma necessidade racional interior à vontade. A noção de moralidade de inspiração kantiana parte da premissa de que o elemento definidor da vida ética está sob o controle do próprio agente e pode ser fruto da determinação exclusiva de uma vontade incondicionada. Segundo Williams, "tal concepção contém uma forma última de justiça no seu íntimo e essa é sua sedução [...], el[a] oferece uma compensação, um consolo a um sentimento da iniquidade do mundo" (Idem, p. 21). Em oposição a essa imagem de uma vontade moral autossuficiente, o filósofo inglês procura discutir o papel que a experiência da fortuna pode desempenhar não apenas no condicionamento das nossas ações, mas também na própria justificação racional que somos capazes de oferecer a respeito delas. A fortuna não seria meramente exterior à vida moral, algo que afetaria seus desdobramentos no mundo, mas não a integridade da intenção moral. Pelo contrário, ela influenciaria e, em algumas circunstâncias, determinaria nossas avaliaçōes e sentimentos morais. Ao enfatizar o problema da "fortuna moral", Williams não tem em mente o puramente acidental, o aleatório, mas sobretudo aquilo que escapa ao controle do agente e que, por força de sua simples efetividade, acontece com ele. Assim, a aceitação sem reservas da ideia kantiana da moralidade só seria possível ao preço de desconsiderar uma série de experiências humanas, de tal modo que uma "vida sem essas experiências envolveria uma reconstrução dos nossos sentimentos e da nossa visão sobre nós mesmos muito mais vasta do que se poderia supor" (Idem, p. 22)

A crítica de Bernard Williams à autossuficiência racional da ética de fundo kantiano traz consigo a possibilidade do questionamento de um dualismo que estaria na base mesma dessa concepção. Tal dualismo é, por assim dizer, paralelo às oposiçōes entre sujeito e objeto, dever ser e ser, ideal e real que inauguram a experiência moderna do mundo e do sujeito. Ele implica cindir a ação em dois polos: em um extremo, o aspecto puramente subjetivo, a intenção do agente e a orientação normativa da sua vontade; no outro, o elemento objetivo, a efetividade do ato e seu desdobrar-se na realidade. A integridade da vida moral, nessa perspectiva, identifica-se com a plena autonomia do sujeito e requer que todo valor esteja colocado no polo da intenção. A afirmação do significado ético da fortuna, em contrapartida, busca negar a estrita separação entre esses dois níveis e nos impede de imaginar uma vida moralmente boa que estivesse desvinculada das circunstâncias em que a atividade moral encontra a sua realização. Abre-se, com isso, a possibilidade de 
deslocar o interesse intelectual de sua concentração prioritária na intenção e na conformação racional da vontade do agente e considerar, também, a ação do ponto de vista de sua prática, de seu fazer-se efetivo. Nesse particular, o pensamento moral da antiguidade parece oferecer um terreno propício à exploração. Como observa Monique Canto-Sperber, a despeito das diferenças entre as correntes filosóficas, seria possível dizer que "a compreensão da vida humana como lugar mesmo da moralidade é comum aos pensadores antigos [...]. Ademais, a vida humana é concebida como uma prática, um agir do qual o homem é o autor. Seu fim é, portanto, uma boa prática (eupragia), um feito, uma forma de sucesso" (2001, p. 89).

O problema da "fortuna moral" não oferece apenas a Martha Nussbaum um ponto de vista a partir do qual abordar um traço distintivo do pensamento moral antigo, ou seja, sua ênfase nos aspectos especificamente práticos da ação. Ao tomar para si esse problema, ela altera o foco da atenção em relação àquele que havia sido o eixo da análise de Bernard Williams. Como vimos, Williams, em seu artigo, tinha como alvo a imagem de que a consciência reflexiva do sujeito moral seria um dado exterior às circunstâncias da deliberação, constituindo, exatamente por isso, a condição da deliberação nas circunstâncias. Dessa forma, ele buscava mostrar que a própria avaliação racional das nossas escolhas morais não é imune à fortuna e que, portanto, o sujeito moral não pode ser pensado fora das condições em que seus julgamentos são feitos. Nussbaum volta sua atenção, prioritariamente, embora não exclusivamente, para os impasses objetivos resultantes da tensão entre a busca de uma vida moral bem-sucedida e as contingências da sua realização. Sendo assim, ela desdobra o problema da "fortuna moral" em três questôes centrais, que são apresentadas no capítulo de abertura do livro e acompanharão o restante da exposição. Tendo em vista a explícita adesão da autora ao "método" aristotélico de abordagem das coisas humanas, creio ser possível dizer que essas três questôes contêm em esboço uma espécie de "fenomenologia" da vida ética humana e do papel que a fortuna aí desempenha. ${ }^{7}$ Em primeiro lugar, diz a autora, atividades e relações que podemos valorizar como parte inseparável de uma boa vida - o amor, a amizade, a atividade política etc. - seriam por definição vulneráveis ao risco, ao perecimento e impregnadas de incerteza. Segundo, as coisas tidas como valiosas são plurais, podem ser incompatíveis entre si e, em última análise, são irredutíveis a um valor superior. Por isso, podem gerar, em circunstâncias que não estão sujeitas ao controle humano, exigências conflitantes e incontornáveis. Terceiro, as emoçōes, os desejos, os sentimentos nos vinculam a objetos, por definição, particulares e contingentes, expondo-nos à precariedade e à indeterminação constitutiva desses últimos. Essa ênfase no papel moral da fortuna fornece alguns dos temas centrais do livro: a dependência da vida moral bem-sucedida em relação a fatores que escapam ao controle dos agentes, a fragilidade dos valores morais humanos e sua vulnerabilidade ao conflito e à contingência, os riscos da crença na possibilidade de eliminação do acaso da existência humana e os limites da pretensão à autossuficiência racional no pensamento ético.

Se levarmos em conta o que foi dito até agora, não chega a ser surpreendente que Martha Nussbaum dedique, como já assinalei, um lugar relativamente reduzido à análise do conceito de tuch no corpus textual dos séculos V e IV a.C. A questão da tuch está, em certa medida, posta de antemão por sua apropriação do problema da "fortuna moral", e a abordagem dos textos se fará sob a forma de um diálogo com esse problema. Não será possível no espaço de que disponho apresentar de forma mais pormenorizada a maneira como a autora desenvolve sua discussão ao longo dos seus capítulos e suas muitas páginas. Somente o contato direto com o texto poderá revelar ao leitor a inteligência e a riqueza das questóes tratadas pelo livro. Como alternativa, retomarei uma afirmação anteriormente citada de Bernard Williams, para expor, de modo algo esquemático, o que considero ser a estrutura geral do argumento. No trecho a que me refiro, Williams dizia que aceitação da crença na imunidade à fortuna e na autossuficiência racional da norma ética exigiriam uma vasta reconstrução da visão que temos sobre nós mesmos. Acredito que essa observação permite pensar a maneira como Martha Nussbaum constrói o seu texto, dividindo-o em três partes. 
Na primeira, "Tragédia: fragilidade e ambição", ela explora os "insights da tragédia" grega (p. xxvii, tradução modificada) sobre os impasses morais decorrentes da exposição da vida humana às contingências da fortuna. $\mathrm{O}$ centro da discussão está na análise dos "conflitos práticos" que os enredos das tragédias oferecem. Tais conflitos surgem da maneira pela qual as circunstâncias restringem as possibilidades de escolha dos agentes, tornando imperativa a decisão entre opções igualmente valiosas, porém mutuamente excludentes nas condições em que se apresentam. A situação de Agamêmnon, que, na tragédia de Ésquilo, se vê obrigado a escolher entre sacrificar sua filha Ifigênia e salvar o exército sob seu comando ou não realizar o sacrifício e levar todos à morte, seria um exemplo desse tipo de dilema. Nele, o agente, embora constrangido pela circunstâncias, preserva sua liberdade de decisão, mas ambas as alternativas a seu dispor o levam à falta e à renúncia a um valor que ele tem por irrenunciável. Nussbaum procura mostrar que os próprios textos trágicos examinam uma solução possível para esses impasses éticos, sob a forma de uma simplificação da estrutura dos compromissos de valor a que prestamos adesão. Em sua análise da Antígona de Sófocles, semelhante "solução" apresentar-se-ia no modo como os personagens buscam recriar a linguagem ética de forma a introduzir em seu interior uma coerência e uma ordem que possam eliminar as exigências conflitantes.

A abordagem dessa "solução" e dos problemas que a acompanham traz para frente da cena uma nova tensão: entre o reconhecimento da vulnerabilidade da vida humana à fortuna e a aspiração a uma ordenação moral da existência que seja capaz de garantir algum controle sobre os acontecimentos e a redução dos conflitos práticos. Segundo Nussbaum, essa aspiração legítima, se levada às últimas consequências, conduziria a um empobrecimento da vida humana tal como a conhecemos e, no final das contas, à sua inteira reconstrução. A tensão entre esses dois polos é um dos eixos do livro e marcará toda a discussão subsequente e, em particular, a análise do pensamento ético de Platão na segunda parte, "Platão: bondade sem fragilidade?".

Platão, como indica o próprio título da seção a ele dedicada, será o portador por excelência de um projeto de imunização da vida ética em relação às contingências e de uma aspiração à autossuficiência racional. Sua filosofia moral seria "motivada por um senso agudo dos problemas causados na vida humana pela fortuna sem controle" (Nussbaum, 2010, p. 80). O pensamento de Platão estaria, portanto, em continuidade com as percepções do teatro trágico, mas caminharia no sentido de elaborar uma reflexão claramente antitrágica. Essa reflexão, pensa Nussbaum, postula, com plena consciência, um tipo de saber que só pode ser alcançado caso nos elevemos para além do meramente humano. Somente a partir dessa posição depurada da falibilidade e da contingência, seríamos capazes pronunciar juízos adequados e propiciar uma orientação correta para nossas vidas. Do alto desse ponto de vista, os valores tornar-se-iam comensuráveis e redutíveis a um princípio único, verdadeiro e estável e, portanto, já não haveria mais motivo para sua colisão; os objetos particulares poderiam ser vistos como a mera expressão contingente de algo permanente e universal e, portanto, os sentimentos, as paixōes e os apetites corporais no seu apego a realidades transitórias perderiam seu apelo e razão de ser. Retomando os termos de Williams, a superação do sofrimento e da dor causados pela experiência da fortuna comprar-se-iam, no platonismo, ao preço de uma "vasta reconstrução" das experiências que reconhecemos e valorizamos como humanas. Martha Nussbaum, porém, não acredita que essa seja a última palavra de Platão. Segundo ela, no Fedro, o filósofo grego teria revisto suas concepçōes sobre as paixões e afeições, para reconsiderar o papel do amor por um ser particular como uma via para a excelência ética. A capítulo dedicado à discussão sobre esse diálogo antecede e prepara a passagem para terceira parte do livro, "Aristóteles: a fragilidade da boa vida humana".

Em sua análise de Aristóteles, Martha Nussbaum procura, de certo modo, responder à seguinte pergunta: qual a abordagem adequada da vida humana e de suas legítimas aspiraçōes a algum tipo de racionalidade moral, tendo em mente o papel que a fortuna aí desempenha? A terceira parte do livro é não só a mais longa, mas também aquela em que mais expressamente o ponto de vista filosófico da autora se entremeia com o dos textos em análise. Aristóteles é apresentado confrontando-se com o desafio 
colocado pelo pensamento de Platão e em busca de uma filosofia moral na medida do humano. Essa última significaria um "retorno a muitos insights e valores da tragédia, uma vez que articula uma concepção de racionalidade prática que tornará os seres humanos autossuficientes de um modo apropriadamente humano" (p. 7, tradução modificada). Após a tentativa platônica de reconstrução racional das bases da ética, a reflexão de Aristóteles implicaria um esforço de restauração no interior da filosofia e por meio da filosofia de uma compreensão da vida moral afinada com "nossa visão sobre nós mesmos", como diria Bernard Williams. A filosofia assumiria um "objetivo terapêutico" (p. 228) e se definiria de forma crítica em relação aos empreendimentos intelectuais que exigem que nos afastemos de nossas opiniōes sobre a natureza da vida moral. Tais opiniōes, ainda que inarticuladas e não raro contraditórias, constituiriam o ponto de partida e, no fim das contas, o limite da própria reflexão filosófica, o dado com que ela tem que se defrontar, caso queira oferecer um conhecimento sobre a experiência humana em que ainda possamos nos reconhecer. Para a autora, a ética aristotélica reata com o mundo da tragédia por ser antropocêntrica (cf. p. 212), sendo levada a assumir a fortuna como condição constitutiva da vida que os seres humanos são capazes de viver. Tal reconhecimento tem um impacto sobre a compreensão do papel da racionalidade prática. Esta última não poderia ser pensada abstraída das circunstâncias, como portadora de princípios universais, em condições de orientar a deliberação nas mais diversas situações. A sabedoria prática requer não só o conhecimento de normas gerais, mas principalmente a percepção dos particulares concretos envolvidos na deliberação. Em Aristóteles, observa Martha Nussbaum, os limites do discurso da filosofia moral estão dados pelos limites do humano, "sua matéria é o bem humano, ou a boa vida para um ser humano" (p. 255). E esse bem, diz ela, por estar exposto à fortuna e ao acaso, é frágil.

\section{Notas}

1 Aristotle's De Motu Animalium. Text with translation, commentary, and interpretive essays. Princeton, Princeton University Press, 1978.
2 Essa é, diga-se de passagem, a primeira tradução de um livro de Martha Nussbaum no mercado editorial brasileiro. Antes disso, havia sido editado um opúsculo (na verdade, trata-se da tradução de uma conferência), denominado A República de Platão: a boa sociedade e a deformação do desejo (Porto Alegre, Bestiário, 2004).

3 Ver, por exemplo, as resenhas de John M. Cooper (1988), T. H. Irwin (1988) e Nicholas P. White (1988) dedicadas ao livro na ocasião do seu lançamento. Os três são especialistas em filosofia clássica e fazem duras restrições ao livro, afirmando que suas interpretações dos textos clássicos se fariam ao preço de distorçôes e omissōes, que, no final das contas, comprometeriam a própria sustentação do argumento filosófico da obra.

4 Como observa Martha Nussbaum, “a 'bondade' do título deve ser entendida como 'o bem humano' ou eudaimonía, e não como 'bondade de caráter”' (p. xiii).

5 Parafraseio aqui as observações de Nicholas P. White na resenha anteriormente citada (1988, p. 137). Para ser mais preciso, cabe observar que Martha Nussbaum discute a noção de tuch no capítulo 4 em relação com o conceito de techn (perícia, arte, ciência). A ênfase dessa discussão, porém, está na análise da ideia de techn e na tentativa de apontar que essa ideia é concebida nos séculos V e IV a.C. como uma forma de controle sobre a tuch. Acompanho as transliteraçôes das palavras gregas propostas no texto original que são, em alguns casos, diferentes das oferecidas na tradução brasileira.

6 O artigo de Bernard Williams é 1976 (Proceedings of the Aristotelian society, vol. 50, 1976) e foi depois incluído no livro Moral luck (1981).

7 Como assinala a própria autora, "toda investigação da relação entre um ser humano com a tuch e com o mundo do acontecimento natural deve, implícita ou explicitamente, oferecer alguma reflexão sobre o que significa ser um animal humano, um ser que tenta controlar a natureza, mas que recebe o efeito e a influência da natureza” (p. 208).

\section{BIBLIOGRAFIA}

BODÉÜS, Richard. (1990), "Resenha de The fragility of goodness: luck and ethics in greek tragedy and philosophy". Dialogue, 29, 1: 144-146.

CANTO-SPERBER, Monique. (2001), Éthiques grecques. Paris, PUF.

COOPER, John M. (1988), "Resenha de The fragility of goodness: luck and ethics in greek tragedy 
and philosophy". The Philosophical Review, 97 (4): 543-564.

DESTRÉE, Pierre. (1993), "Resenha de The fragility of goodness: luck and ethics in greek tragedy and philosophy". Revue Philosophique de Louvain, 91 (89): 138-140.

IRWIN, T. H. (1988), "Resenha de The fragility of goodness: luck and ethics in greek tragedy and philosophy". The Journal of Philosophy, 85 (7): 376-383.

KNOX, Bernard. (1986), "Theater of ethics" (resenha de The fragility of goodness. Luck and ethics in greek tragedy and philosophy). The New York Review of Books, 33 (19). Disponível em <http://www.thegreatideas.org/95w/ TGIO276.pdf>, acessado em 9/9/ 2011.

NUSSBAUM, Martha. (2001), The fragility of goodness: luck and ethics in greek tragedy and philosophy. 2. ed. Cambridge, Cambridge University Press.

TAYLOR, Charles. (1988), "Critical notice” (resenha de The fragility of goodness: luck and ethics in greek tragedy and philosophy). Canadian Journal of Philosophy, 18 (4): 805-814.

WHITE, Nicholas P. (1988), "Rational self-sufficiency and Greek ethics" (resenha de The fragility of goodness: luck and ethics in greek tragedy and philosophy). Ethics, 99 (1): 136-146.

WILLIAMS, Bernard. (1981), Moral luck. Cambridge, Cambridge University Press.

WOODRUFF, Paul B. (1989), "Resenha de The fragility of goodness: luck and ethics in greek tragedy and philosophy". Philosophy and Phenomenological Research, 50 (1): 205-210.

\section{BERNARDO FERREIRA é professor da área de Ciência Política no Departamento de Ciências Sociais da Universidade do Estado do Rio de Janeiro (UERJ). \\ E-mail: <bferreira@openlink.com.br>.}

\section{"Vinculos" e "nós" no centro da explicação da pobreza urbana}

Eduardo Cesar MARQUES. Redes sociais, segregação e pobreza. São Paulo, Editora da Unesp/Centro de Estudos da Metrópole, 2010. 216 páginas.

\section{Sandra Gomes}

O livro Redes Sociais, Segregação e Pobreza, de Eduardo Marques, traz um novo olhar sobre a questão da produção e reprodução da pobreza urbana no contexto das cidades contemporâneas. Partindo do entendimento de que a pobreza é fenômeno multidimensional, ou seja, não se trata apenas de ausência ou insuficiência de renda como também diz respeito ao "acesso aos mais importantes benefícios das sociedades urbanas modernas" (p. 30), o estudo introduz um novo elemento analítico às discussões clássicas sobre a questão: as relaçôes sociais como condicionantes da integração social de um indivíduo.

A partir de uma revisão crítica de conceitos atrelados de diferentes maneiras à questão da pobreza - como estrutura de oportunidades, efeitos de vizinhança, segregação residencial, capital social e redes sociais -, o autor apresenta o eixo norteador do livro. O estudo propóe-se a abrir a "caixa-preta" de um dos mecanismos explicativos das condições de vida de um indivíduo: as redes sociais. Para isto, o autor adota uma estratégia de pesquisa que combina análises quantitativas com qualitativas. Num primeiro momento, apresenta medidas sobre as redes pessoais dos indivíduos em situação de pobreza lançando mão de sociogramas como ferramenta metodológica -, de forma a caracterizá-las e verificar quais as associações existentes entre essas e outros indicadores socioeconômicos. Num segundo momento, emprega-se uma análise de cunho mais qualitativo - entrevistas em profundidade - que permite compreender como as redes sociais efetivamente afetam as trajetórias de vida dos indivíduos.

Como o autor chama a atenção inúmeras vezes, tal procedimento visa a extrapolar o uso metafórico de redes sociais presente em parte do debate associado à pobreza, como, por exemplo, nas discussões que revisa sobre o conceito de capital social. Além disso, faz uma crítica muito pertinente à boa parte da literatura que discute os "efeitos de vizi- 